\title{
Discourses on Family Time: The Cultural Interpretation of Family Togetherness in Los Angeles and Rome
}

\author{
Tamar Kremer-Sadlik \\ Marilena Fatigante \\ Alessandra Fasulo
}

\begin{abstract}
In this article, we examine U.S. and Italian parents' discourses on family time in parentfilled weekly activity charts and interviews with parents. Analysis indicates that in Los Angeles, California, parents talk about sheltering and isolating their nuclear family from the outside world and from everyday routine by creating special times and special activities for the nuclear family. In contrast, Roman parents' discourse allows for spontaneous times with the family that are diffused within routines and merged with other community members, institutions, and social spaces. We argue that differences displayed in parents' discourses are shaped by culturally specific orientations toward time, family, and individual versus shared responsibility. Through this cross-cultural comparison we contribute to the understanding of how local cultural models shape different ways in which parents interpret time spent in family and influence individuals' perceptions of their everyday lives. [family, time, responsibility, United States, Italy].
\end{abstract}

Family time in the United States is often aligned with Quality Time ideology - a concentrated, unstressed, and uninterrupted time dedicated to activities parents and children do together - to make up in quality for what may be missed in quantity (Daly 1996, 2001; Galinsky 1999; Kremer-Sadlik and Paugh 2007). Indeed, U.S. popular media, as well as academic research encourages parents to find Quality Time that the family can share (Kraehmer 1994; Plionis 1990). An initial examination revealed the absence of this expression in Italian discourse when applied to family life. Both cultural views on time and family life and preferences regarding how time should be spent in family shape the meaning assigned to the term family time. In this article we seek to understand the meaning of family time for working parents in two different cultural contexts, in Rome, Italy, and Los Angeles, California (hereafter, "LA").

\section{Discourses on Time}

\section{Time As a Commodity}

Time has been a topic of inquiry for thousands of years. Newton, with the development of science, considered time as a measure of motion and as such, a quantity indefinitely divisible into units. With enlightenment a shift took place from the ontology of time (asking what it 
is) to the epistemology of time (questioning the knowledge of time). In Kant's theory, time is an intuition preceding experience and perception, and as such, it is in the human mind. Hegel, expanding on Kant's theory, suggests that time is not a condition of perception, but of consciousness, and that rather than existing a priori, it is constructed and formed in the mind. Hegel's theory places time in two important realms, that of phenomenology, within which time is linked to the experiential self, and that of the social world, within which it is connected to historical processes (Adam 2004).

The mechanical clock, appearing first in the 14th century, influenced greatly the understanding of time. No longer relying on seasons and growth, the mechanical clock divided the diurnal cycle into even, accurate, abstract, decontextualized, neutral units (Dohrn-Van Rossum 1998). Further, the mechanical clock (miniaturized and portable) allowed dislocation of control over time from the public sphere to a personal, internalized discipline (Adam 2004). The development of clock time was a prerequisite to a shift in the perception of time to its valuation as a commodity.

Marx (1976) was the first to recognize how certain economic systems, specifically capitalism, treat time as a resource, as a commodity. In his labor theory of value, he explains that to pay workers for their time rather than for their products, time has to become an abstract, independent value linking money to goods and services. Only the quantitative, divisible time of the clock can be translated to and equated with money. When time is money, speed becomes of utmost importance. Further, when speed is equated with efficiency, time compression and conflict are inevitable. Marx (1976) recognized that time was linked to other social systems and relations and that as such, time is at the heart of conflicts and tensions at the intersections of different temporal spheres, such as community and private life, work and home.

Focusing on time and treating it as a commodity, as a resource, has permeated numerous areas of social science. Most notably, Time Use studies examine, on a micro level, individuals' daily sequences of activities, and, on a macro level, the balance among time allocations to various activities of people in different groups (Gershuny 2000). The point of departure is that "if we can measure how members of society spend their time, we have the elements of a certain sort of account of how that society works" (Gershuny 2000:1). Time Use studies have successfully provided a quantified depiction of people's management of everyday life.

Nonetheless, the Time Use studies approach has a number of disadvantages. It uses a narrow definition of human activities emphasizing duration in time. As Ås explains: "we speak of activities only insofar as we can locate points in time that constitute the beginning of these behavior units. Activities are segments of time" (1978:126). Furthermore, to measure and compare time allocations, Time Use studies use fixed categories such as paid work, domestic work, leisure, and child care, collapsing human activities into manageable gross categories; thus missing the infinite variations that constitute daily life. Most importantly, this conceptualization of human behavior ignores fundamental relational and experiential aspects of time (Adam 2004; Paolucci 2004) especially the varied meanings people attach to certain times of the day and to activities that take place within them. 


\section{Experiencing Time}

The experiential dimension of time has been traditionally opposed to its quantified, "clocked" dimension. Researchers have tried to capture this difference in numerous ways: linear time versus cyclic time (Adam 2004; Geertz 1973); time of being versus time of existing (Balducci 1986); and clocked time versus event time (Levine 1997).

Levine (1997) defines "event time" as the perception of and focus on activities to mark and make sense of time flow, rather than attending to the time these events inhabit. Events, such as sunrise, the birth of a child, meals, regular visits to extended family, and the like, mark the passing and the duration of time. The relevance of these events is subordinated to the social and contextual meaning attributed to these occurrences. Conversely, in "clocked time," the individual is concerned with the passing of time and with the way it is allocated to events. In clocked time, one may feel responsible for the ways segments of time are filled with activities and may try to exert control over time use feeling efficient when activities are accomplished within a certain time frame (Gasparini 2000). When bounding activities within time markers, individuals not only distinguish these activities as separated from others, but can also forecast their occurrence and duration. Hence, control and responsibility are key to understanding differences in the perception and management of time.

\section{(Post)Modern Discourses on Time}

Viewing human behavior as sequences in time allocated to fixed categories of activities adheres to the conception of time as a zero-sum resource. Thus, as Southerton (2003) points out, one set of practices squeezes the time for other sets of activities resulting in a perceived time shortage. English phrases like time starvation, time crunch, and Italian expressions like il tempo è tiranno (time is a tyrant) have become semantic labels for capturing this perception. Ironically, this notion is contradicted by Time Use studies that tell us that individuals have more free time (unallocated time) than ever before (Robinson and Godbey 1997), yet people continuously feel that modern society is inflicted with time famine and that daily life is hurried by contrast with an idealized interpretation of the past (Southerton 2003).

This attitude toward time appears twofold: on the one hand, individuals are instructed with solutions on how to manage, design, and control time, as the rise of self-help books evidences (Larsson and Sanne 2005). On the other hand, individuals are alerted not to fall into the "time trap" (MacKenzie 1997) and to seek instead the experience of time freed from hurriedness and achievement, where continuity and fullness of being is found in interstitial, casual, unpredictable moments of the day (Gasparini 2005; Piazza 2005).

\section{Family Time}

The label family time appeared first in the mid-19th century. Before the Victorian era, family time was unmarked and inseparable from work or communal times (Gillis 2001, 2003). Recently, much attention has been given in the United States to the notion of family time 
owing to a growing perception that in contemporary society, with the increase in dualearner families (U.S. Bureau of Labor Statistics 2005) and working hours (Gornick and Meyers 2004), parents and children do not have enough time together. This perception is intensified by a tendency to romanticize the past and long for a condition that may have never existed. As Gillis notes "we all have two families, one that we live with and another we live by" (1996:xv). The desire to (re)constitute an ideal image of the family, not influenced by the modern hurried pace of life, has led to the need for creating a special time for being together, set apart from the mundane rhythm of everyday life (Daly 1996, 2001; De Vault 2000; Gillis 1996). The "special-ness" of this time, however, seems to characterize more the concept of time for family in the United States in comparison to other European countries (Harkness and Super 2006).

Yet in many Western societies a notion of family time has become, we propose, a symbolic locus where family members connect and experience each other as a relational unit, and a moral expression of being a family. We further suggest that discourses on family togetherness, regardless of differing cultural understandings of its meaning and manifestation, encompass a morality of the "right" way of being family and parents. Below, we analyze Roman and LA parents' accounts of their daily lives to explore the underlining cultural ideologies regarding how time should be spent together.

\section{The Ethnography of Family Time}

The data for this study were collected as part of a 32-working-family research project conducted by the Center on the Everyday Lives of Families (CELF) at the University of California, Los Angeles (UCLA), and the eight-working-family research project conducted by the Italian Center on the Everyday Lives of Families (iCELF) at the Università di Roma. Analyses rely on parent-filled weekly activity charts and interviews with parents.

The LA families selected to participate in the study by responding to a newspaper ad. The Roman families were informed about the study through schools. In both sites, families consisted of two parents, both working 30 hours or more per week outside the home. Participants self-reported a range of education levels, ranging from high school to graduate degrees with the majority holding a bachelor's degree, and a variety of professions from clerical and technical to high management and academic positions. Parents' ages varied with LA mothers ranging from 31 to 48, LA fathers from 28 to 52, Roman mothers from 34 to 47, and Roman fathers from 39 to 55. Each family had two or three children (35 girls and 38 boys in the LA sample, 10 girls and six boys in the Rome sample), with at least one child between the ages of eight and 10 (in LA children's ages ranged from one to 17 years of age, in Rome from 1.5 to 13). Fifty percent of LA families relied on after-school childcare services, the rest picked up their children at the end of the school day (around three p.m.). All Roman families sent their elementary school children to tempo pienno, an after-school program offered at no additional pay. The LA families owned their homes and paid a mortgage. 
The Roman families either owned or rented their homes. The LA families came from diverse ethnic backgrounds and lived in different neighborhoods within the Greater LA area. The Roman families lived in various neighborhoods in Rome. No recent immigrants participated in the study. No information regarding religious affiliation was collected.

\section{Artifacts of Family: Weekly Activity Charts}

Parents were given charts (a chart per family member) divided into seven weekdays and each day into three parts (morning, afternoon, and evening) and were asked to fill out the children's and their own daily activities for a typical week. Parents were told that the main purpose of the charts was to get a sense of the activities that make up each family member's day and that listing the activities was more important than ordering and timing.

Latour and Woolgar (1979) suggest that written documents should be treated as representations created by actors to make sense of events in their lives. Rather than treating the weekly charts as accurate reflections of event types and durations, we analyze the weekly charts as mapping devices that expose parents' preferences regarding which events to note and how to describe them, thus illuminating particular schemas and orientations toward their everyday lives. Features of language such as lexicon, morphology, and style, were analyzed suggesting that particular linguistic choices made by parents strategically contribute to the construction of their interpretations of the task of filling out the charts and their representations of activities that constitute their weekly routines (Duranti 1997:ch. 2; Ochs 1992).

\section{Accounting for Family Togetherness: The Interviews}

As part of the research procedures, CELF and iCELF researchers conducted a number of interviews with parents. The interviews were transcribed and the segments addressing the topic of family time were analyzed. LA interviews were conducted in English. Roman interviews were conducted in Italian and relevant segments are translated here.

Interviews were analyzed within the frameworks of linguistic anthropology and discourse analysis that approach language as a form of social action (Duranti 1997). Thus, speech, rather than a mirror of individual thoughts and beliefs, is treated as achieving particular social acts, for example, of alignment with or rejection of a particular belief, justification for one's action, evaluation of another, and more. In this sense, parents' talk about family time offers insights into their ways of constructing a particular version of the topic, exposing their socially and culturally informed meanings regarding family, work, children, morality, and responsibility. In their discourse, parents also engage in a process of self-description and presentation (Goffman 1959), constructing a particular version of themselves as moral parents. Further, talk is coconstructed, in that it involves both speaker and audience; it is designed for particular interlocutors and shaped by their reactions to the initial talk (Billig 1987; Potter and Wetherell 1987). Specifically, research on interviews has highlighted the 
coconstructed nature of interview accounts where meaning cannot be interpreted without reference to the interactional context of their production (Briggs 1986; Houtkoop-Steenstra and Antaki 1998).

It is important to note that the interviewers-authors are members of the communities they have studied, and thus are informed of sociocultural norms and preferences regarding family life. For example, the interviewers' shared cultural assumptions are displayed implicitly in the way questions are posed about paid work that parents bring home. In Excerpt 2 below, the interviewer asks, "We wanted to know the number of hours, eh spent at home during workdays on activities linked to work, if there are any." In this instance, hesitation, pauses, and expansion on the request divulge the interviewer's treatment of the topic of paid work entering the family space as sensitive. By adding the coda "if there are any," the option of working at home is presented as a diminished alternative and displays (indexing cultural preferences) the interviewer's reduced expectation that this option will be selected by the parent. Hence the moral weight carried by such a question is embedded in the formulation of the interviewer's turn and is likely to influence the response (Heritage and Sefi 1992). The coconstructive nature of interlocutors' talk is not unique to interview settings, but is inherent to natural interaction (Goodwin 1981; Sacks 1992). Finally, by examining parents' language use both in charts and interviews, our analyses here focus solely on parents' representations of their daily routines and on their ideologies regarding time spent with family members, rather than on their actual practices.

\section{Parents' Weekly Charts}

On examining the weekly charts, it became apparent that in most families mothers tended to fill out the charts for their children and sometimes for their husbands as well, and that mothers' charts provided most details about family routines. The charts also reveal that times when family members were together were most frequently noted on weekends. Therefore we focus here on mothers' charts and their descriptions of weekend family activities. The translation of the Roman charts into English is as literal as possible to capture the particular words and grammatical structures mothers chose to use. Data are interpreted against a broader background of ethnographic research and knowledge of cultural uses of language. Overall the charts reveal variation in the details and time allocation for activities both in the LA and the Roman data, however, we will also highlight trends that emerged in each locale.

\section{Segmentation of Time and Activities}

In both corpuses, mothers often used clocked time to segment their weekend schedules into timed activities. Despite these similarities, the charts filled in by mothers in LA tended to show a higher degree of segmentation of activities and certainty in their occurrence, whereas the Roman charts displayed more unpredictability and uncertainty with regard to the 
weekend activities. Chart 1 below reveals numerous mini activities that constitute the weekend routine of one LA mother. (Note that within chart entries by mothers bold indicates segments particularly relevant to analysis.)

In this chart, as in other charts in the LA corpus, routines are often mentioned as a list of miniactivities that are accomplished within a certain time frame. For example, in Chart 1 the mother lists five activities ("watch TV," "read aloud," "hang out with kids," "get kids ready," "put them to bed") between seven p.m. and nine p.m. on Saturday to denote two hours that the family spends together. The tendency to segment, specify, and package activities one after another in such a fashion, emphasizes the activity-driven quality of time spent together. The use of the simple present tense (known as "habitual present") as in watch, read, bang out, get, and put depicts these activities as routine, habitual, and certain occurrences. Furthermore, in the LA charts certain events are often broken down into the subactivities that they encompass. For example, in Chart 1, on both Saturday and Sunday, mother notes the following: "4:00 start getting things together for dinner, 5:00 cook dinner, 6:00 eat dinner, 6:30 clean up kitchen." Specifying the details that are involved in having dinner (preparation, eating, cleaning) emphasizes the work that is put into it and the necessity of accomplishing practical tasks (incl. feeding the family), rather than the relational experience of having a meal together. The perception that dinner requires time and effort is further reiterated in parents' interviews when they talk about their difficulty finding time to cook dinner and feed their family healthy meals.

CHART 1. Segmentation of Activities: Certainty (LA Mother, two children ages 6 and 10)

\begin{tabular}{|c|c|c|}
\hline & Saturday & Sunday \\
\hline Morning & $\begin{array}{l}\text { 8:30- wake up, take shower, eat breakfast, } \\
\text { make up, get dressed, household chores } \\
\text { 11:00- run errands, laundry, hang out with } \\
\text { kids }\end{array}$ & $\begin{array}{l}\text { 8:30- wake up, take shower, eat breakfast, make } \\
\text { up, get dressed, household chores } \\
\text { 10:30- go to church } \\
\text { 11:30- church over }\end{array}$ \\
\hline Afternoon & $\begin{array}{l}\text { 12:30- lunch (make, eat) } \\
\text { 1:00- chores (laundry, gardening, cleaning) } \\
\text { 4:00- start getting stuff together for } \\
\text { dinner }\end{array}$ & $\begin{array}{l}\text { 11:45-1:00- go to in-laws to visit, have lunch } \\
\text { 1:00- go home, household chores, play w/kids } \\
\text { 4:00- start getting things together for dinner }\end{array}$ \\
\hline Evening & $\begin{array}{l}\text { 5:00- start cooking dinner } \\
\text { 6:00- eat dinner } \\
\text { 6:30- clean up kitchen } \\
\text { 7:00- watch TV/video w/kids, read } \\
\text { aloud, hang out w/family, get kids ready } \\
\text { for bed, put them to bed (9pm) } \\
\text { 9-11:30- watch TV, laundry, chat on } \\
\text { phone, go out w/friends sometimes }\end{array}$ & $\begin{array}{l}\text { 5:00- cook dinner } \\
\text { 6:00- eat dinner } \\
\text { 6:30- clean up kitchen } \\
\text { 7:00- get kids ready for bed, get things ready for } \\
\text { next day } \\
\text { 8:00- put daughter to bed, read aloud } \\
\text { 8:30- put son to bed } \\
\text { 9:00- go back to work to prepare for following } \\
\text { week. } \\
\text { 11:30- return home }\end{array}$ \\
\hline
\end{tabular}


CHART 2. Segmentation of Activities: Options (Roman Mother, two children ages 7 and 11)

\begin{tabular}{|c|c|c|}
\hline & Saturday & Sunday \\
\hline Morning & $\begin{array}{l}9.30 \text { wake up } \\
10.00 \text { breakfast } \\
10.30 \text { tiding up the house, laundry, a little shop- } \\
\text { ping, assisting children with homework, a little } \\
\text { bit of cooking }\end{array}$ & $\begin{array}{l}9.30 \text { wake up } \\
10.00 \text { breakfast } \\
10.30 \text { various chores (work, too) or go for a } \\
\text { walk, or a day trip (especially to the sea- } \\
\text { side) }\end{array}$ \\
\hline Afternoon & $\begin{array}{l}13.30 \text { lunch } \\
15.30 \text { - going out, take Federico [to a youth orga- } \\
\text { nization meeting], shopping for home and family } \\
\text { or chores, potentially work }\end{array}$ & $\begin{array}{l}13.30 \text { lunch or picnic } \\
14.30 \text { continuation of previous activities, } \\
\text { potentially the Movies, sometimes close } \\
\text { family, sometimes friends or relatives }\end{array}$ \\
\hline Evening & $\begin{array}{l}20.00 \text { Dinner by ourselves or with some friends } \\
20.30 \text { watching TV a little bit with the family or } \\
\text { reading }\end{array}$ & $\begin{array}{l}\text { 17.45 Dinner } \\
\text { The same as on weekdays }\end{array}$ \\
\hline
\end{tabular}

In contrast, Roman mothers' notations of weekend schedules present chores and activities as tentative and optional. In Chart 2, the Roman mother suggests possible activities for the weekend schedule. This is evident through the prevalent use of the conjunctive or (appearing seven times) and the adverbs possibly and potentially to note alternative activities that the family may or may not engage in during the weekend. This open-endedness depicts weekend activities as less habitual and less predictable, and chores as less necessary to accomplish. This attitude toward chores is further marked through the use of the diminutives (e.g., "a little bit of cooking"), which modify the noun (e.g., cooking) and mitigate the character of the chore as less demanding. The unpredictable duration of activities is also evident in the notation "continuation of previous activities" on Sunday afternoon. A sense of casual-ness with regards to the time activities may occupy arises as the mother portrays the day as full of different options. This stands in contrast to the detailed schedule delineated in the LA charts. Last, in contrast to the segmentation of dinner into separate tasks found in the LA chart, the Roman mother only uses a single word, cena (dinner), encompassing in this single event both the practical (chorelike) activities of preparing and serving dinner and the social relational elements that constitute it.

\section{Marking Family Events}

In 28 of the 32 families in the LA study, activities when family members got together were qualified and labeled as family activities. They included examples such as family breakfast, family dinner, and family movie (see Chart 3).

The use of the label family to qualify activities indicates that their primary goal is for the family to be together and that they are tailored for that goal. Hence, family movie is not just any movie but one appropriate for children (i.e., denotes a certain rating), and family breakfast, distinguished from breakfast (as noted on weekdays) may suggest that the food served 
CHART 3. Marked Family Activities (LA Mother, two children ages 8 and 10)

\begin{tabular}{|c|c|c|}
\hline & Saturday & Sunday \\
\hline Morning & $\begin{array}{l}\text { 7:00- wake up } \\
7: 00-8: 00 \text { - read paper } \\
8: 00-8: 30 \text { - make family breakfast and eat it } \\
9: 00-1: 00 \text { - do laundry between activities }\end{array}$ & $\begin{array}{l}7: 00-8: 00 \text { - wake up } \\
8 ; 00-8: 30 \text { - read paper } \\
8: 00 \text { or } 9: 00 \text { - make family breakfast and eat }\end{array}$ \\
\hline Afternoon & $\begin{array}{l}\text { 110:00-2:00- attend soccer games } \\
4: 00-5: 00 \text { - supermarket, run errands } \\
5: 00 \text { - fold laundry } \\
5: 30 \text { - make dinner }\end{array}$ & $\begin{array}{l}\text { 10:00-5:00- go to birthday party, visit grandpar- } \\
\text { ents, work on school projects, have play-dates }\end{array}$ \\
\hline Evening & $\begin{array}{l}\text { 6:00- eat dinner } \\
\text { 7:00-9:00- watch family movie, have sleep- } \\
\text { over, go for walk } \\
\text { 10:00-11:00- to bed }\end{array}$ & $\begin{array}{l}\text { 6:00-7:00- make and eat dinner } \\
\text { 7:00-8:00- shower kids } \\
\text { 8:00-8:30- kids to bed } \\
\text { 9:00- make lunches, exercise, watch TV, read } \\
\text { 10:00- adults to bed }\end{array}$ \\
\hline
\end{tabular}

matches children's preferences (e.g., pancakes and waffles) and that all members of the immediate family would eat together. The association of child-designed activities with family events is prevalent in LA parents' interviews as will be seen below. Also, labeling activities as family ones excludes others, nonfamily persons, from being part of the event, from joining in. Hence, family-designed activities seem to never overlap with other social time (friends are rarely mentioned in the LA charts).

Mothers in LA also noted the term family time as a specific activity occurring on weekends (see Chart 4). Equating family time with a clearly bounded activity foregrounds family togetherness as separated from other activities and participants. The use of the formulaic term family time without elaboration suggests that mothers treat it as a known category, a culturally shared type of activity, folding into one category the varied social and emotional experiences constituting this time.

In contrast, none of the Roman mothers marked activities with any "family"-like term. There is no corresponding idiom in the Italian language to the English term family time, and the category itself does not seem to emerge. Analysis of Roman mothers' charts suggest that it is the social event, such as dinner or an outing, which often includes friends, rather than the orientation toward the family, which is explicitly labeled and marked. This preference is further attested in the parents' interviews below.

In Chart 2 above, the Roman mother mentions a number of social activities that may take place on Sunday (such as "go for walk or a day trip" and "lunch or picnic"). There is no explicit mention of who might participate in these activities. However, we know from interviews and ethnographic data that Roman families often go away for the weekend (three of our eight families own a weekend home in the country). Although the mother does not 
CHART 4. "Family Time" as Activity (LA Mother, two children ages 5 and 8)

\begin{tabular}{|c|c|c|}
\hline & Saturday & Sunday \\
\hline Morning & $\begin{array}{l}\text { 8:00 wake up } \\
\text { 8:15 breakfast for kids/me } \\
\text { 8:30 Shower, get dressed shopping } \\
\text { 9:00-12:30 Either run errands or stay } \\
\text { home: laundry, garden, housework, sort } \\
\text { recycling }\end{array}$ & $\begin{array}{l}8: 00 \text { wake up } \\
8: 30 \text { breakfast } \\
8: 45 \text { or 9:00 shower, get dressed } \\
\text { 9:00-12:30 Either run errands or stay home } \\
\text { stuff (see Sat.) }\end{array}$ \\
\hline Afternoon & $\begin{array}{l}\text { 12:30 Lunch } \\
\text { 1:00-5:00 More of same: yard work, } \\
\text { housework, garden, laundry, errands } \\
\text { 5:00 prepare dinner }\end{array}$ & $\begin{array}{l}\text { 12:30 Lunch } \\
\text { 1:00-5:00 More of same: (see Sat.) } \\
\text { 5:00 prepare dinner }\end{array}$ \\
\hline Evening & $\begin{array}{l}\text { 6:30 dinner (or go out) } \\
\text { 7:00 - 9:00 Family time } \\
\text { 9:00 ish — kids to bed } \\
\text { to } 11: 00 \text { or 12:00 watch TV, read }\end{array}$ & $\begin{array}{l}\text { 6:30 dinner } \\
\text { 7:00 - 8:00 Family time } \\
\text { 8:00 kids bath } \\
\text { 8:15 get kids stuff ready for Mon (Jonas'sheets, } \\
\text { so laundry must be done!) } \\
\text { 9:00 kids to bed/watch TV or read } \\
\text { 10:00 Mom to bed }\end{array}$ \\
\hline
\end{tabular}

specify whether these optional activities include the whole family, we know that the family spends their weekends in the country and that they are all together there. Thus, this chart illustrates the preference for noting social activities without marking the family. Family togetherness, rather than a marked event, is presented as an understood, assumed condition. The absence of emphasis on the nuclear family is further apparent in the mother's suggestion that Sunday afternoon can be potentially spent with, either the nuclear family, friends, or relatives. The following Roman chart (see Chart 5) further highlights how the experience of being together can be strongly associated with an event and setting, rather than with the activities and participants.

In this chart the social time reported on Saturday evening reflects time together diffused both temporally and interpersonally; the term serata (translation: an evening, but rather than indexing time of day, which in Italian is sera, serata denotes a duration and a social experience), similarly to passeggiata (going to the seaside) on Saturday afternoon, qualifies the event as a continuous, open-ended flow of time. It also emphasizes the social and leisure design of the event itself. The extended duration of the evening and the different possible participants (parents, children, parents' friends, and children's friends), offer an opportunity within which participants can engage in activities and experience intimacy in a spontaneous manner. Interestingly, the mother chooses to provide information about the setting rather than about the activities that take place. The setting is the country home fireplace, camino, a place that evokes qualities of warmth and intimacy. Finally, the reference to both generations (parents and children) and their respective friends marks this social event as having the two generations mingle while having their own proper space and time together. 
CHART 5. "Family Time" Diffused across People and Settings (Roman Mother, two children ages 9 and 12)

\begin{tabular}{|c|c|c|}
\hline & Saturday & Sunday \\
\hline Morning & $\begin{array}{l}10.30 \text { wake up-breakfast } \\
11.30 \text { shopping } \\
14.00 \text { lunch with friends }\end{array}$ & $\begin{array}{l}11.00 \text { wake up } \\
11.30 \text { breakfast } \\
12.00 \text { seaside } \\
14.00 \text { Pizza on the beach }\end{array}$ \\
\hline Afternoon & $\begin{array}{l}15.00 \text { "passeggiata al mare" [going to the } \\
\text { seaside] } \\
16.30 \text { Dora horses } \\
19.00 \text { home, homework + cooking }\end{array}$ & $\begin{array}{l}16.00 \text { home, garden, } \\
\text { homework with Leo and Dora }\end{array}$ \\
\hline Evening & $\begin{array}{l}21.00 \text { cena [dinner ] } \\
\text { camino [fireplace] }+ \text { children }+ \text { our } \\
\text { friends + children's friends }+ \text { serata [eve- } \\
\text { ning] } \\
24.30 \text { bed }\end{array}$ & $\begin{array}{l}20.00 \text { cena [dinner] } \\
21.00 \text { Departure [from the country home] } \\
22.20 \text { home } \\
23.00 \text { bed }\end{array}$ \\
\hline
\end{tabular}

The analysis of the Roman and LA mothers' charts have highlighted some important differences in interpreting and expressing times family members are together. We have seen the tendency to view togetherness as an activity-driven exclusive time for the family in the LA charts and the proclivity of Roman mothers to characterize times together as more fluid across activities and participants. Next, we look at parents' interviews to examine the ways in which both fathers and mothers talk about spending time together with their family members.

\section{Parents' Interviews}

\section{Making Time for Family}

Talk about times spent together with family members occurred spontaneously as parents described their weekly schedules and responded to various questions regarding different aspects of their lives. Emerging in those instances were parents' views and beliefs about what is "good" and "proper" time spent with family. In doing so parents engaged in a moral discourse providing evaluations, explanations, justifications, and accounts regarding a "right" way of being a family and good parents.

Immediately apparent in both LA and Roman parents' talk is the importance of preserving time for family, especially because work can become ubiquitous and easily dip into family life. In Excerpt 1 below (see Appendix 1 for transcription conventions), an LA mother explains that they carve time for family by making Sunday their "family day," and simultaneously admits that work can infringe on that time, as happened "this past Sunday" (1. 3). 
Excerpt 1- "We try our hardest"

(LA family, three children, ages 8, 4 1/2 and 1)

1. Mother: Then on Sundays we try our hardest- it's definitely a family day to us.

2. We don't leave each other or the kids on Sundays, unless we have to.

3. I worked this past Sunday, but-

4. but we usually do not leave each other on Sundays.

Providing time for family is also made explicit by the Roman father in Excerpt 2 below, when he answers a question about the amount of hours he spends on paid work while at home. In his response father suggests that, when the family is home, the world (of work) does not infringe; it remains outside.

Excerpt 2-"The world is left outside"

(Roman family, two children, ages 9 and 13)

1. Researcher: A:nd actually we wanted to know the number of hours,

2. eh spent at home during workdays on activities linked to work, if there are any.

3. eh: so whether- it's difficult I understand ((smiling voice))

4. Father: It's di:fficult because you can't tell: the mi:nutes = because

5. when we come home, eh we come home, we just stop [Italian: 'si chiude' = 'one

6. stops']. Because there are the kids, (.) there's dinner. When we are with them, the

7. world is left outside.

Parents in LA also emphasize the import of family togetherness by equating it with a religious sentiment of sacredness. In Excerpt 3 below, an LA mother explains that dinnertime during the week, when everyone is at work and school most of the day, is the only time that they can be together and that "that's kind of a sacred time."

Excerpt 3 - "To me that's kind of a sacred time"

(LA family, two children, ages 10 and 6)

1. Mother: ... dinner, which is really the only time of the day during the week

2. that we really get a chance to, umm, you know,

3. sit and talk about the day and things like that together as a family. 
4. When a lot of families don't do that- and I think-

5. or they watch TV or, you know, do whatever, during dinner time,

6. and they just kind of miss that opportunity.

7. To me, that- that's kind of a sacred time.

The link between "sacredness" and specific times is also made by a Roman mother, who in response to a question about working on weekends, declares that time is "sacred," not to be contaminated by work. It is interesting to note that it is the interviewer who provides an interpretation for how "sacredness" may be manifested by equating it with dedicating this time to the family.

Excerpt 4- “The Weekend Is Absolutely Sacred"

(Roman family two children, ages 9 and 13)

1. Researcher: ... do you ever happen to work on weekends?

2. Mother: Well, uhm: (.) only if I'm on a business trip.

3. (1.0) Or if a business trip is coming up and I have a nearing deadline.

4. On the contrary, the weekend is absolutely sacred.

5. Researcher: Uhm, so you de- dedicate it uh: to yourselves, let's say

6. Mother: Yes.

7. Researcher: To the family. Alright.

Although both parents in LA and in Rome articulate the importance of preserving time for family, especially against the pushes and pulls of work, a closer examination of their discourses reveal a number of significant differences. In Excerpt 1, the LA mother emphasizes the family's commitment to having a family day and the struggle and uncertainty of being able to be together ("we try our hardest," 1. 1) because of competing demands (e.g., work). She depicts the accomplishment of not leaving one another as a purposeful effort and choice made by the whole family, using the pronoun we to include all members (1. 2). The effort required to achieve this family day not only casts it as worthy, but also heightens the morality of the action; the work that it takes to be together is the "moral quest for the good" (MacIntyre 1984).

The morality of the deliberate pursuit of time for family is further emphasized in the LA mother's talk in Excerpt 3. The depiction of dinner as the only time that the family can be together during the week identifies it as a special time for family. Further, by being aware of how others do not eat together and instead engage in inappropriate activities ("watch TV" 
1. 5) and by contrasting these practices with her own, this mother highlights her effort to protect the opportunities of being together as family. The sacredness of dinner that mother evokes is derived from the intense involvement in and the isolation of the family event by avoiding being distracted and contaminated by other less valuable ("whatever," 1. 5) activities.

In contrast, the Roman parents in the two excerpts above do not portray family togetherness as laborious and its achievement as an accomplishment but, rather, as a matter-of-fact reality of family life. In Excerpt 2, the protection of family space from work interference is not portrayed as requiring effort, but rather as a family policy (see the use of we framing the behavior as a collective) of drawing a door between the nuclear family and the work environment (1. 5). The use of the diminisher adverbial just further implies that the potential force of the action is limited (Quirk et al. 1985). The obviousness of togetherness is reinforced by the use of the existential there ("there are the kids, there's dinner"), which depicts being together as a fact rather than a conscious choice. The father's formulation "the world is left outside" (1. 7) assertively closes the turn and glosses the entire description as a moral obligation to which he is committed. A similar definiteness is displayed in Excerpt 4, when the Roman mother evokes the morally loaded word sacred to clarify that work does not interfere with family life. The packaging of the meaning of this time into a single word and the emphatic addition of the adverb of certainty absolutely depict the "sacredness" of the weekend as given and undisputable, and the spending of time with family as obvious and unceremonious.

The perception that family togetherness is accomplished away from the work world is taken a step further to include the social world when the LA parents below recount that they literally separate the family from others.

Excerpt 5- "We say 'no' to people”

(LA family, three children, ages 8, $41 / 2$ and 1)

1. Father: Usually. Yeah we don't usually plan much.

\section{We plan for us.}

3. Mother: We just try to, yeah,

4. and we say "no" to people that ask us for plans sometimes.

By turning down invitations from others, parents isolate and shelter the nuclear family, facilitating attending to its members, especially to children, and avoiding being distracted by others. In this sense, the meaning of family time (and more broadly of family) is linked to the experience and the desire of privacy and separation from the outside world that threatens to draw family members away from one another. 
The Roman parents in our study, although clearly preferring a division of the worlds of work and family, do not seem to separate the family from the social world, even one that may have links to work. In Excerpt 6 below, a Roman father, responding to a question about working at home on weekends, launches into a narrative in which work and family mesh in a positive way with clients who are also good friends with whom the family goes out in the evenings.

Excerpt 6-"We go together. We are a big group"

(Roman family, two children, ages 9 and 13)

1. Father: We have friends, who are our cli:ents. They have children,

2. and they are my children's friends. And we meet and we go out for dinner =

3. Now we will leave, we go together. We are a big group, (.) and and mh: =

4. one couldn't say whether this is part of the [work] world = YES:

5. N:O. Who knows?

The way the father sequentially builds his report broadens and diffuses the experience of togetherness beyond the nuclear family to other people. By wondering whether "one couldn't say whether this is part of the [work] world" (1. 4), the ideal of the separation between the two spheres is problematized, and, consequently, we argue, the idea of a (nuclear) family-designed time is questioned as well.

The analysis thus far reveals that whereas in the LA parents' interviews emphasis is put on personal effort to carve special time and activities for the family, Roman parents do not similarly stress the effort of accomplishing a prescribed way of being together. Differences in the relative weight assigned to times and activities dedicated to the nuclear family are also evident from a quantitative summary of the family activities mentioned in the interviews. Of the 32 LA families, 29 raised the topic of family activities during their interviews. Recall that talk about such activities came about spontaneously as this was not a topic covered in the interview protocol. Of these families, five only briefly mentioned their occurrence (e.g., "Saturdays we just go out and play in the park," or "After church we go out to dinner and then we come home."). The remaining 24 families (75 percent of the LA families), beyond mentioning activities, expressed their belief and preference regarding ways of being together often associated with Quality Time ideology (e.g., "Usually we go to one place together, a park or whatever," and "... trying to do something with the kids that's fun for them."). The Roman parents' interviews, unlike the majority of LA data, did not portray activities in which the family engaged with an ideological preference toward organizing special time, or specific activities. All but one of the families mentioned routine activities they do together (e.g., "On Saturday and Sunday ... we like to run errands, we like to think 
of the coming week" and "It happens that she chooses a book and we read it for her"). The difference between designed and routine activities is also evident in the following excerpts.

\section{Being Together: Prescription versus Routine}

As we have seen in Excerpt 1, our LA parents often refer to weekend as their family time. The LA mother in Excerpt 7 below describes the family's typical Sunday routine, emphasizing the type of activities the family engages in to experience what she explicitly characterizes as "family time."

Excerpt 7- "A museum counts as family time too"

(LA family, two children, ages 8 and 5)

1. Mother: We'll do something like go to a museum or something and- you know.

\section{It counts as family time too.}

3. It could be- yeah, there's a kids' museum.

Although the mother begins by reviewing generic options ("something like," 1. 1) of activities that the family would do together, she evokes the label "family time" as a superordinate category that the specific activity "going to a museum" exemplifies. The prescriptive meaning of the verb "count" and the adverb "too" (1.2) at the end of the sentence constitute "going to a museum" as a normative practice of "family time." Thus, the mother suggests (1) that there is an expectation that the family will orient to normative practices of "family time" during that day, (2) that certain activities are better than others in capturing "family time," that is, not just any museum but a child-designed "kids' museum" (1. 3.) Thus, for this mother, as for many of our LA parents, the way of being together and doing "family time" requires special times and specific activities, in particular child-oriented activities.

Rather than emphasizing a prescribed way of being together, Roman parents, as the father in Excerpt 8 below, regularly highlight routines and certain time interstices (i.e., time "in between" other main activities such as work or school) as opportunities for experiencing relational time.

Excerpt 8- "This is the thing I am really protecting"

(Roman family, two children, ages 7 and 11)

1. Father: Then, I bring them [the children] to school, sometimes one, sometimes the other.

2. and this is the thing that I am really protecting. I mean,

3. I'm trying to keep the possibility of getting to work at an unfixed time, 
4. between nine and ten.

\section{At least in this way, I mean at least we dress together, \\ 6. we leave the house together, \\ 7. I take them to school. I meet other parents, other children. I mean \\ 8. this is the space that $I$ am protecting.}

This father depicts coparticipation in mundane everyday activities as opportunities for parent-child togetherness. At the same time, he marks his effort to preserve these opportunities (1. 2), and, depicts them as minimal (see the use of the adverb "at least" appearing twice in 1. 5), indicating that they do not fulfill the ideal for being together. He proposes a way to cope with the time constraints of everyday life by exploiting resources available to him. In contrast with instances in which family togetherness is identified within the nuclear family, this father refers to the possibility of meeting other children and parents (1. 7) as part of the relational time with his children; attending to the children's world includes participation in their lives outside the family.

LA parents also refer to routines when addressing relational moments with their children, yet the emphasis is on the special-ness of the moment, rather its ordinariness.

Excerpt 9- “That's her time, that quiet time together"

(LA family, two children, ages 10 and 6)

1. Mother: But when I put Becky to bed, that's her time-

2. our kind of gossip and chitchat and stuff.

3. And when I do that with Tim, too, we talk about his day and stuff.

4. It's kind of a good way for him to unload and- and,

5. you know, for us to kind of have that- that quiet time together.

For this mother the routine of putting her children to bed is an opportunity for engaging in certain activities - gossiping, chitchatting, and talking. Ordinary practices are cast as privileged moments specifically dedicated to the child ("that's her time" and "it's a good way for him") as well as to the mother-child dyad ("our kind of gossip"). By using the determiner "that" in "have that quiet time together," the mother indexes "quiet time together" as a known and understood notion of time, linking it to the moral discourse of dedicating special time to children's interests. 


\section{Quality Time: Effort and Guilt}

As is shown above, the Roman parents depict times and activities with family as matter-offact realities, embedded in routines and involving other people. Yet there is one exception. The Roman father in the excerpt below treats family togetherness in a similar way to the LA parents, doubting whether an intimate moment with his daughter sitting on his lap counts as time together, as quality time, if rather than making an effort, he engages in a mundane activity of watching a match on TV.

Excerpt 10- "It's not quality of time spent together"

(Roman family, two children, ages 8 and 1.5)

1. Father: And then there is the sense of guilt for the time spe:nt,

2. for the quan- the quantity and the quality of time spent//with children

3. Researcher://mh. quantity and quality. The quality too.

4. Father: mh: one spent some time together with Beatrice on one's lap

5. watching the soccer match from- on television, but, it's not

6. quality of- of- of time spent together.

7. Father: (.) on the other hand. I cannot deny that with a little more effort

8. less la:ziness a bit of willingness, one could do more.

\section{This is the sense of guilt that one carries with oneself}

10. which possibly $=$ one solves,. $\mathrm{h}$ with all the toys that he gives.

According to this father, the achievement of quality time requires a purposeful effort; the moral decree is that parents should be more "willing" and less "lazy" (1. 8), and not resort to shortcuts such as buying toys (1. 10). Thus, quality of time with his daughter, and by extension the quality of his parenting, is measured based on the amount of effort he puts into attending to his daughter, and engaging in appropriate activities (that would interest the child rather than the adult). Failing to do so results in guilt because "one could [always] do more." In this father's eyes, he is the one responsible for achieving or failing to achieve quality time with his family. This echoes the Quality Time ideology prevalent among the LA parents. 


\section{Discussion}

Looking through the lens of the atypical Roman case, the rhetoric embedded in the U.S. Quality Time ideology reveals its pitfalls: the acceptance of a prescribed way of "doing" being together as a family results in pressure for the individual to match normative expectations toward what counts as "good" and "right" time for family (see also LA Excerpt 7 "It counts as family time"). As the Roman father points out, "It's not quality of time spent together," if it does not match the prescription, thus highlighting his awareness of the existence of an external pressure that dictates the moral way of being together. Furthermore, the internalization of normative expectations, we propose, causes a person to feel individually responsible for reaching the prescribed, the ideal form of togetherness; the expression "one could do more" (1. 8; also see LA Excerpt 1 "We try our hardest"), elucidates the idea that achieving quality time solely lies on parents' shoulders, on the parents' willingness and effort. Finally, the focus on individual responsibility suggests that any gap between the ideal and reality is rooted in parents' actions and therefore results in their feelings of failure and of guilt.

This belief stands in contrast with the Roman parents' written and oral reports in which the experience of togetherness is neither explicitly marked as family time, nor is it dedicated or restricted to particular kinds of activities, places, or people. For the most part, these parents convey the expectation that family togetherness emerge spontaneously in the routine, that it is "nested" within the meaning of the event itself (e.g., "passeggiata al mare" or "serata") and therefore is open to improvisation and change.

Wetherell (2003) notes that interviews expose the cultural resources individuals have at their disposal "for telling their patch of the world" (Wetherell 2003:13). In this sense, the collective voice of culture permeates the individual voice. Extending this idea to our interview and chart data, we propose that individual parents' discourse on family togetherness in this study represents a collective voice of their community with its practices, preferences, and beliefs. Psychological anthropological theories (D'Andrade and Strauss 1992; Harkness and Super 1996, 2006) have suggested that cultural models motivate and influence parents' perceptions, choices, and practices within the constraints presented by a culture. Levine (1997), as discussed earlier, has argued that members of different societies tend to construct time culturally and experience it either as "event time," where the focus is on events to mark and make sense of time flow, or "clocked time," where the concern is with the passing of time and with the way it is allocated to certain activities. In "event time" individuals inhabit time, in "clocked time" they feel responsible for how time is used and try to exert control over it. We propose that the similarities and in particular the differences between the LA and Roman parents' perceptions of what counts as family time mirror culture-specific orientations toward time and family. The understanding of these concepts, as we argue below, is dependent on local cultural interpretations and public discourses regarding individual versus communal responsibility. 


\section{Individual Family Responsibility versus Family Partnership with the State}

There is much evidence to suggest that in the United States time is typically constructed as "clocked time." Zerubavel points out how temporal organization is based "on forcing activities in a systematic way into rather rigid temporal patterns" (1982:130), thus highlighting two important aspects of time: that its definition is rooted in the activities that inhabit it, and that time involves intentional, purposeful control over the occurrence of certain activities in certain time slots. The purposefulness of time is also evident in the view of leisure activities, which, rather than being experienced as unclocked time with no purpose, are envisioned as goal-driven "recreation": a set of activities with a function to improve one's life, e.g., one's health, skills, and relationships (Gillis 2001; Shaw and Dawson 2001). The prevalence of self-help books that regularly offer advice about how to use one's time and activities to better control one's life, further enhance the perception that time needs to be managed and controlled and that it is the individual who can and should do it (Larsson and Sanne 2005). Finally, as the analyses above illustrate, our LA parents' discourses reflect the tendency to perceive time as slots occupied with activities. We propose that the cultural preference of "clocked time," which enhances the sense of responsibility regarding how time is used, paired with certain characteristics of the U.S. family result in a particular understanding of family time.

The individualistic and independent characteristics of the early U.S. family coupled with Protestant Ethics, which emphasize individual responsibility and self-reliance - if one makes the right choices, one will succeed and will achieve salvation - have been principal forces in shaping U.S. culture (Demos 1976; Dyer 1979; Sanchez-Burks 2002; Skolnick 1991; Weber 1930). Historically the U.S. government has been concerned with protecting private rights and with defending citizens' interests and profits without having public, moral authority (Bellah 2002; Kramnick 2003). The laissez fair approach has led to a suspicion, still prevalent today, of universal and "one size fits all" governmental programs that are viewed as restricting and threatening individuals' freedom to choose, and at the same time leaving individuals responsible for finding solutions to societal problems (Putnam 2000).

The emphasis on individual responsibility and the defense of autonomy against the tyranny of the state contributed to the treatment of the nuclear family as a private subject outside the control and care of the government (Swindler 2002). Thus, when faced with difficulties such as work-family conflict and time shortage, families are expected and expect themselves to resolve the problem and provide a solution, as Kornbluh (2004:1) explains, "We tend to view the problem of family time as a private problem that can be solved by individual families and employers acting on their own." This has been sharply noted in the absence of profamily U.S. legislation that could provide families with more time, such as paid maternal leave and paid family leave.

We propose that the perception of the family as self reliant coupled with the cultural preference for "clocked time," which enhances the sense of responsibility regarding how time is used, result in the United States in the emergence of Quality Time ideology, as a prescribed 
ideal way of being together, as the primary solution to the family-work conflict (KremerSadlik and Paugh 2007).

In Italy, the success of books like The Meridian Thinking (Cassano 1996), which promotes the "southern" approach to everyday life, calling for experiencing everyday life rhythms and events without making time "productive" (cf. Cassano 2001), illustrates a cultural preference, particularly in Central and South Italy, for perceiving time use more as a collective rather than an individual achievement, and a dislike of the notion of personal control over time and activities (cf. Putnam et al. 1994). A large sociological literature (Balbo 1991; Balbo and Nowotny 1986; Paolucci 1998) promotes in political and social arenas the idea of time as open to forms of solidarity and collective management, diffused in social spaces such as neighborhoods and the city (Belloni 1984). In these studies the family appears as one among other social institutions in which time can be individually and collectively experienced. This idea stands in striking contrast to the prevalent U.S. interpretation of family time as a private matter of the nuclear family.

Contrary to viewing it as a private entity, the public and institutional status of the Italian family as a "primordial societal cell" was recognized early on in the Italian Constitution (Art. 29). Article 31 further states that it is a governmental duty to support the family both economically and socially and to protect both children and parents. Family policies have been a great part of the Welfare State, especially since the 1970s, when women advocated for the need to establish public childcare services and extended school day both to allow the balance of work and family life and to provide children with equal opportunities in education and care (Di Nicola 2002; Saraceno 1998).

The public discussion in Italy positions the family as a partner of a broader network of institutions (the state, public services, the education system, the church). The idea that family responsibilities can be diffused across institutions beyond the nuclear family is visible in governmental legislation such as the implementation of the paid parental leave law (since 1971 for mothers, and recently extended to any parent, L. 53/2000). The time for care, which family-friendly policies address, also encompasses ways in which individual and family well-being can be reached through regulation of time in broader social contexts. Embedded in the parental leave is the requirement of local administrations to coordinate the tempi della città, such as the opening and closing hours of offices and shops, school time, timetables of public transportation, and adjust them to the multiple life schedules of working people and working parents in particular (Leccardi 2005).

Interestingly, the expression "tempo per le famiglie" [time for families], refers to local programs developed in childcare centers in which parents come to centers to spend time with their young children. Family time is thus an opportunity offered and monitored by the institution for parents and children to experience each other. These initiatives also present opportunities for parents to meet other parents, discuss common concerns and ideas, and receive advice from expert staff in order to better cope with the demands of childcare and 
to avoid the possible isolation of the nuclear family in contemporary urban contexts (Comune di Sesto Fiorentino [Municipality of Florence] 2007). This formulation of family time presents it as a time for family members' connectedness that is not only facilitated by the institution but is also broadened to include other people rather than the nuclear family only.

\section{Concluding Thoughts}

The analyses of LA and Roman parents' discourses on time for family reveal that these parents present different ways in which family members protect the family from outside demands. In LA, to be together, parents talk about sheltering and isolating their nuclear family from the outside world and from everyday routine by creating special times and special activities for the family, thus reproducing the sociocultural context of individual responsibility and the laissez faire approach of the institutions. The orientation toward individual responsibility over family-time allocation resonates with de Certeau's (1984) notion of "strategies," which refer to ways in which ordinary people reclaim autonomy and control from various institutions. De Certeau argues that when individuals' in their everyday life are faced with a system that imposes on them in different ways (e.g., the need to find time for family), they have two options for action; strategies or tactics. According to de Certeau, when one employs strategies, one creates their own space, where one has power and control, where one experiences mastery over time, autonomy, and predictability. Strategies, thus, resemble, the predictable, prescribed slots of special time dedicated to family found in the LA data. The LA mother in Excerpt 7 who states that a museum "counts as family time" is employing an existing strategy (i.e., going to the museum) to achieve being together as a family.

Roman parents' discourses reveal a perception that routines and everyday events offer opportunities that family members can spontaneously utilize and improvise to be together, thus merging family time with other community members and social spaces. The diminished sense of responsibility for finding time for family converges with the Italian public discourse that expresses an expectation that the state and its institutions participate in protecting the family sphere, hence reinforcing the partnership between the state and the family. The Roman parents seem to cope with the need to find time for family by using what de Certeau calls tactics. Tactics refer to the ability to "take advantages of 'opportunities," that is, to improvise in the moment. When the Roman father in Excerpt 8 recounts how he experiences time with his children by getting ready together in the morning, he indicates that he exploits the existing constraints of everyday life turning them into improvised resources.

Using a detailed discourse analysis we have shown how, although the issue of preserving time for family is a concern for both LA and Roman parents, they frame it in different ways according to interpretive schemas that are rooted in the sociohistorical realities of their communities and that resonate with public discourses. Through this cross-cultural comparison of parents' discourses, we hope to have contributed further to the understanding of how local cultural models regarding time, family, and individual versus shared responsibility 
shape different ways in which parents interpret time spent in the family and more generally influence individuals' perceptions of their everyday lives. Regarding Time Use studies, which aspire to learn how societies work through a detailed documentation of how members spend their time, we argue for the value of enriching such research with qualitative methods to examine in detail people's experience of time and what motivates them to perceive and explain their time use in particular ways.

\begin{tabular}{ll}
\hline Appendix 1: Transcription Conventions & \\
\hline$?$ & Raised intonation \\
$\cdot$ & Falling intonation \\
$:$ & Elongated speech \\
$\frac{\text { no }}{{ }^{\circ} 0^{\circ}}$ & Emphasis \\
CAPITAL & Quiet speech \\
$/ /$ & High volume \\
$=$ & Speech overlap \\
- & Contiguous utterances \\
$()$. & Cut-off or self-interruption \\
$(1.0)$ & Pause between utterances \\
$(($ action $))$ & Pause of 1 second \\
{[]} & Non-verbal action \\
$\ldots$ & Authors' comments \\
bold & Skipped speech \\
\hline
\end{tabular}

TAMAR KREMER-SADLIK is a postdoctoral fellow and director of research of the Center on Everyday Lives of Family at the department of Anthropology, UCLA.

MARILENA FATIGANTE is a postdoctoral fellow in the Department of Developmental and Social Psychology at the Sapienza University of Rome.

ALESSANDRA FASULO is a senior researcher and lecturer in the Department of Developmental and Social Psychology at the Sapienza University of Rome.

\section{References Cited}

Adam, Barbara

2004 Time. Malden, MA: Polity Press.

Ås, Dagfinn

1978 Studies of Time-Use: Problems and Prospects. Acta Sociologica 21(2): 125-141.

Balbo, Laura, ed.

1991 Tempi di Vita: Studi e Proposte Per Cambiarli (Times of Life: Studies and Bids for Change). Milano: Feltrinelli.

Balbo, Laura, and Helga Nowotny, eds.

1986 Time to Care in Tomorrow's Welfare Systems. Vienna: Eurosocial. 
Balducci, Ernesto

1986 Il Cerchio che si Chiude (The closing circle). L. Martini, ed. Genova: Marietti.

Bellah, Robert N.

2002 Meaning and Modernity: America and the World-Epilogue. In Meaning and Modernity:

Religion, Polity, and Self. Richard Madsen, William M. Sullivan, Ann Swindler, and Steven

M. Tipton, eds. Pp. 255-276. Berkeley: University of California Press.

Belloni, Carmen

1984 Il Tempo della Città:Una Ricerca sull'Uso del Tempo Quotidano a Torino (The time of the city: A research on the use of everyday time in Turin). Milano: Franco Angeli.

Billig, Michael

1987 Arguing and Thinking. Cambridge: Cambridge University Press.

Briggs, Charles L.

1986 Learning How to Ask: A Sociolinguistic Appraisal of the Role of the Interview in Social

Science Research. Cambridge, MA: Cambridge University Press.

Cassano, Franco

1996 Il Pensiero Meridiano (The meridian thinking). Roma-Bari: Laterza.

2001 Modernizzare Stanca: Perdere Tempo, Guadagnare Tempo (Modernity weakens: Losing time, earning time). Bologna: Il Mulino.

Comune di Sesto Fiorentino (Municipality of Florence)

2007 Tempo per le Famiglie: Uno Spazio per la Coppia Adulto-bambino (Time for families: A space for the adult-child dyad). Electronic document, http://www.melograno.org/

Daly, Kerry J. tempofamiglie.htm, accessed on January 18, 2008.

1996 Families and Time: Keeping Pace in a Hurried Culture. Thousand Oaks, CA: Sage.

2001 Deconstructing Family Time: From Ideology to Lived Experience. Journal of Marriage and Family 63(2): 283-294.

D'Andrade, Roy. G., and Claudia Strauss

1992 Human Motives and Cultural Models. New York: Cambridge University Press.

De Certeau, Michel

1984 The Practice of Everyday Live. Berkeley: University of California Press.

Demos, John

1976 Myths and Realities in the History of American Family Life. In Contemporary Marriage:

Structure, Dynamics, and Therapy. Henry Grunebaum and Jacob Christ, eds. Pp. 9-31.

Boston, MA: Little, Brown.

De Vault, Marjorie L.

2000 Producing Family Time: Practices of Leisure Activity beyond the Home. Qualitative Sociology 23(4): 485-503.

Di Nicola, Paola

2002 Prendersi Cura delle Famiglie (Taking care of families). Roma: Carocci.

Rossum, Dohrn-Van Gerhard

1998 History of the Hour: Clocks and Modern Temporal Orders. Chicago: University of Chicago Press.

Duranti, Alessandro

1997 Linguistic Anthropology. Cambridge: Cambridge University Press.

Dyer, Everett D.

1979 The American Family: Variety and Change. New York: McGraw-Hill.

Galinsky, Ellen

1999 Ask the Children: What America's Children Really Think About Working Parents. New York: William Morrow.

Gasparini, Giovanni

2000 La Dimensione Sociale del Tempo (The social dimension of time). Milano: Angeli.

2005 Plint. Il Piccolo Libro degli Interstizi (Plint. The small book of interstices). Roma: Editori Riuniti. 
Geertz, Clifford

1973 Person, Time and Conduct in Bali. In The Interpretation of Cultures. Pp. 360-411. New York: Basic Books.

Gershuny, Jonathan

2000 Changing Times: Work and Leisure in Postindustrial Society. Oxford: Oxford University Press.

Gillis, John R.

1996 A World of Their Own Making: Myth, Ritual, and the Quest for Family Values. Cambridge, MA: Harvard University Press.

2001 Never Enough Time: Some Paradoxes of Modern Family Time(s). In Minding the Time in Family Experience, Contemporary Perspectives in Family Research. Kerry J. Daly, ed. Pp. 19-37. Thousand Oaks, CA: Sage.

2003 Childhood and Family Time: A Changing Historical Relationship. In Children and the Changing Family: Between Transformation and Negotiation. An-Magritt Jensen and Lorna McKee, eds. Pp. 149-164. New York: Routedge Falmer.

Goffman, Erving

1959 The Presentation of Self in Everyday Life. New York: Anchor.

Goodwin, Charles

1981 Conversational Organization: Interaction between Speakers and Hearers. New York: Academic.

Gornick, Janet C., and Marcia K. Meyers

2004 Families that Work: Policies for Reconciling Parenthood and Employment. New York: Russell Sage.

Harkness, Sara, and Charles Super

1996 Parents' Cultural Belief Systems: Their Origins, Expressions, and Consequences. New York: Guilford.

2006 Themes and Variations: Parental Ethnotheories in Western Cultures. In Parental Beliefs, Behaviors, and Parent-Child Relations: A Cross-Cultural Perspective. Kenneth H. Rubin and Ock Boon Chung, eds. Pp. 61-79. New York: Psychology Press.

Heritage, John, and Sue Sefi

1992 Dilemmas of Advice: Aspects of Delivery and Reception of Advice in Interactions between

Health Visitors and First Time Mothers. In Talk at Work: Interactions in Institutional

Settings. Paul Drew and John Heritage, eds. Pp. 359-417. Cambridge: Cambridge

University Press.

Houtkoop-Steenstra, Hanneke, and Charles Antaki

1998 Creating Happy People by Asking Yes-No Questions. Research on Language and Social

Interaction 30(4): 285-313.

Kornbluh, Karen

2004 Hearing on "Parents Raising Children: The Workplace." Testimony before the

Subcommittee on Children and Families of the Committee on Health, Education, Labor and

Pensions, U.S. Senate, April 22, 2004. Washington, DC: U.S. Government Printing Office.

Kraehmer, Steffen T.

1994 Quantity Time: Moving Beyond the Quality Time Myth. Minneapolis: Deaconess Press.

Kramnick, Isaac

2003 A Moral Republic: Public and Private in the Political Thought of the Founders. In Public and Private in American History: State, Family, Subjectivity in the Twentieth Century. Rafaella

Baritono, Daria Frezza, Alessandra Lorini, Maurizio Vaudagna, and Elisabetta Vezzosi, eds. Pp. 13-30. Torino, Italy: OTTO editore.

Kremer-Sadlik, Tamar, and Amy Paugh

2007 Everyday Moments: Finding "Quality Time" in Working Families. Time and Society 16(2-3): 287-308.

Larsson, Jörgen, and Christer Sanne

2005 Self-Help Books on Avoiding Time Shortage. Time and Society 14(2-3): 213-230. 
Latour, Bruno, and Steve Woolgar 1979 Laboratory Life: The Social Construction of Scientific Facts. Beverly Hills, CA: Stage.

Leccardi, Carmen

2005 I Tempi di Vita tra Accelerazione e Lentezza (The life times between acceleration and slowness). In Tempo Vola: L'esperienza del Tempo Nella Società Contemporanea. Franco Crespi, ed. Pp. 49-85. Bologna: Il Mulino.

Levine, Robert 1997 A Geography of Time. New York: Basic.

MacIntyre, Alasdair 1984 After Virtue. Notre Dame: University of Notre Dame Press.

MacKenzie, Alec 1997 The Time Trap. New York: AMACOM.

Marx, Karl 1976[1867] Capital, Volume 1. Harmondsworth, UK: Penguin.

Ochs, Elinor

1992 Indexing Gender. In Rethinking Contexts. Alessandro Duranti and Charles Goodwin, eds. Cambridge: Cambridge University Press.

Paolucci, Gabriella

1998 La Città: Macchina del Tempo, Politiche del Tempo Urbano in Italia (The city: A time engine, policies of urban time in Italy). Milano: Franco Angeli.

. 2004 Uso e Percezione del Tempo: Una Falsa Dicotomia (Use and perception of time: A false dichotomy) http://www.tempiespazi.toscana.it/culture/testi/uso/

Piazza, Marina

2005 Un Po' di Tempo per Me: Ritrovare se Stessi, Vivere Meglio (A Bit of Time for Myself: Finding Oneself, Living Better). Milano: Mondadori.

Plionis, Elizabeth Moore

1990 Parenting, Discipline and the Concept of Quality Time. Child and Adolescent Social Work 7(6): 513-523.

Potter, Jonathan, and Margaret Wetherell

1987 Discourse and Social Psychology: Beyond Attitudes and Behaviour. London: Sage.

Putnam, Robert

2000 Bowling Alone: The Collapse and Revival of American Community. New York: Simon and Schuster.

Putnam, Robert, with Robert Leonardi and Raffaella Nanetti

1994 Making Democracy Work: Civic Traditions in Modern Italy. New Jersey: Princeton University Press.

Quirk, Randolph, with Sidney Greenbaum, Geoffrey Leech, and Jan Svartivik

1985 A Comprehensive Grammar of the English Language. Harlow, UK: Wesley Longman.

Robinson, John P., and Geoffrey Godbey

1997 Time for Life: The Surprising Ways Americans Use their Time. University Park:

Sacks, Harvey Pennsylvania State University Press.

1992 Lectures on Conversation. Cambridge, MA: Blackwell.

Sanchez-Burks, Jeffrey

2002 Protestant Relational Ideology and (In)Attention to Relational Cues in Work Settings. Journal of Personal and Social Psychology 83(4): 919-929.

Saraceno, Chiara

1998 Mutamenti della Famiglia e Politiche Sociali in Italia (Family changes and social policies in Italy). Bologna: Il Mulino.

Shaw, Susan M., and Don J. Dawson

2001 Purposive Leisure: Examining Parental Discourses on Family Activities. Leisure Sciences 23(3): 217-231.

Skolnick, Arlene

1991 Embattled Paradise: The American Family in an Age of Uncertainty. New York: Basic. 
Southerton, Dale

2003 "Squeezing Time": Allocating Practices, Coordinating Networks and Scheduling Society. Time and Society 12(1): 5-25.

Swindler, Ann

2002 Saving the Self: Endowment versus Depletion in American Institutions. In Meaning and Modernity: Religion, Polity, and Self. Richard Madsen, William M. Sullivan, Ann Swidler, and Steven M. Tipton, eds. Pp. 41-55. Berkeley: University of California Press.

U.S. Bureau of Labor Statistics

2005 Table 4. Families with Own Children: Employment Status of Parents by Age of Youngest Child and Family Type, 2004-5 Annual Averages. Electronic document, http://www.bls.gov/

Weber, Max news.release/famee.t04.htm, accessed May 22, 2008.

1930 The Protestant Ethics and the Spirit of Capitalism. New York: Routledge.

Wetherell, Margaret

2003 Racism and the Analysis of Cultural Resources in Interviews. In Analyzing Race Talk:

Multidisciplinary Approaches to the Interview. Harry Van Den Berg, Margaret Wetherell, and Hanneke Houtkoop-Steenstra, eds. Pp. 11-30. Cambridge: Cambridge University Press.

Zerubavel, Eviatar

1982 Schedules and Social Control. In Time and Aging: Conceptualization and Application in Sociological and Gerontological Research. Barry Ephraim, Mizruchi Glassner, and Thomas Pastorello, eds. Pp. 129-146. Bayside, NY: General Hall. 